\title{
Role of Fructose Malabsorption in Patients With Irritable Bowel Syndrome
}

\author{
Young Kim and Chang Hwan Choi* \\ Department of Internal Medicine, Chung-Ang University College of Medicine, Seoul, Korea
}

\author{
Article: Prevalence of fructose malabsorption in patients with irritable bowel syndrome after excluding small intestinal \\ bacterial overgrowth \\ Jung KW, Seo M, Cho YH, et al \\ (J Neurogastroenterol Motil 2018;24:307-316)
}

Irritable bowel syndrome (IBS) is one of the most common functional gastrointestinal disorders. About $5-11 \%$ of the population in most countries is assumed to have IBS. ${ }^{1}$ The symptoms of this disorder include recurrent abdominal pain or discomfort related to bowel habit changes that continue for $>6$ months, causing heavy burden on the quality of life of some affected persons. ${ }^{1,2}$ The mechanism behind IBS is considered to be multifactorial, including altered motility, visceral hypersensitivity, altered gut microbiota, and dysfunction of the brain-gut axis and the immune system. ${ }^{1,2}$ Likewise, there are multiple treatment options for this disorder, and selecting the appropriate treatment may be challenging for patients and clinicians in the presence of limited evidence. ${ }^{1}$

Recent studies have shed new insights about the role of food on the etiologies of IBS. There are many evidences indicating that certain foods cause IBS symptoms. The elimination diets, such as low fermentable, oligosaccharides, disaccharides, monosaccharides, and polyols (FODMAPs), have been shown to alleviate symptoms. Fructose is a monosaccharide that is increasingly consumed as dietary habits become Westernized worldwide. The more extensive use of fructose-containing artificial sweeteners and high-fructose corn syrup are definitely contributing to this increased intake. ${ }^{5,6} \mathrm{~A}$ French cohort study showed that this Westernized dietary pattern moderately increased the risk of IBS, ${ }^{7}$ and one of the reported foodrelated etiologies of IBS is fructose malabsorption (FM).,

The ability of the human intestines to absorb fructose is limited. Specific intestinal fructose transporters (glucose transporter-5) in the intestines of humans may be easily overwhelmed by fructose $>$ 50 g. ${ }^{10}$ FM leads to a variety of gastrointestinal intolerance symptoms that resemble the symptoms presented by patients with IBS. When patients with unexplained symptoms were administered 50 $\mathrm{g}$ fructose and underwent breath tests, $73 \%$ tested positive for elevated hydrogen or methane, providing evidence of FM. Moreover, approximately $80 \%$ of these positive-tested patients experienced symptoms such as flatus, pain, bloating, belching, and altered bowel habit. ${ }^{11}$ The osmotic load that the unabsorbed fructose creates passes into the colon, which houses a variety of fermenting microbiomes that produce these unpleasant symptoms. ${ }^{8}$

The physiological connection between FM and IBS is becoming more concrete. Patients with IBS without small intestine bacterial overgrowth (SIBO), confirmed with the glucose hydrogen

Received: March 19, 2018 Revised: None Accepted: March 19, 2018

(c) This is an Open Access article distributed under the terms of the Creative Commons Attribution Non-Commercial License (http://creativecommons. org/licenses/by-nc/4.0) which permits unrestricted non-commercial use, distribution, and reproduction in any medium, provided the original work is properly cited.

*Correspondence: Chang Hwan Choi, MD, PhD Department of Internal Medicine, Chung-Ang University College of Medicine, 102 Heukseok-ro, Dongjak-gu, Seoul 06973, Korea Tel: +82-2-6299-1418, Fax: +82-2-6299-2017, E-mail: gicch@cau.ac.kr 
breath test (HBT), who were loaded with $25 \mathrm{~g}$ fructose showed symptomatic FM and fructose intolerance without malabsorption in $22 \%$ and $28 \%$, respectively. ${ }^{12}$ Forty-four percent of patients experiencing functional bowel disorders showed FM after being administered $25 \mathrm{~g}$ fructose, whereas $60 \%$ showed improvement after lowering the fructose level in their diet. ${ }^{13}$ Another study observed that $52 \%$ of patients with IBS had FM, in contrast to $16 \%$ of the control group and the IBS patients with FM tended to be IBS-D (IBS with predominant diarrhea) type. ${ }^{14}$

Many evidences about the relationship between FM and IBS highlight the importance of HBT that is a safe, inexpensive, and noninvasive modality for diagnosing carbohydrate malabsorption. The HBT is clinically applied to assess carbohydrate malabsorption in patients with dietary restrictions, such as those under a low fermentable carbohydrate diet (eg, FODMAP) ${ }^{15,16}$ Other clinical uses of this test include diagnosing SIBO and measuring the orocecal transit time. ${ }^{17,18}$ However, there are several problems. The HBT is not yet a standardized test, and SIBO may increase the positive rates of FM when measured using the glucose HBT, because this test cannot measure fermented gas produced by bacteria in distal small intestine. $^{18}$

In the current issue of the Journal of Neurogastroenterology and Motility, Jung et $\mathrm{al}^{19}$ published a prospective, controlled study that investigated the prevalence of FM in patients with IBS and in asymptomatic controls after excluding SIBO with the glucose HBT. By excluding patients with a diagnosis of SIBO, attempts were made to better objectively assess the possible relationship between FM and IBS. The 25-g fructose HBT identified FM at a significantly higher percentage in SIBO-negative patients with IBS than in asymptomatic controls, suggesting that FM may be associated with IBS.

The study by Jung et $\mathrm{al}^{19}$ shows the link between IBS and FM; however, it has a few limitations. First, this study included 10 (29\%) patients with IBS-C (IBS with predominant constipation). As FM usually presents symptoms related to IBS-D or IBS-M (IBS with mixed bowel habit), the results might have been somewhat altered by including patients with IBS-C. It might have led to better results if only patients with IBS-D and IBS-M were included. Second, as aforementioned, the glucose HBT can not detect bacterial overgrowth in the distal small bowel; thus, some patients classified as having FM might have included those with SIBO.

The prevalence of SIBO is generally higher in patients with IBS than in healthy persons. ${ }^{17,20,21}$ If SIBO is present, the symptoms associated with FM may become worse owing to bacterial fermentation in the small intestine and in the colon. Therefore, investigating how FM and SIBO interact with each other and lead to the development of IBS symptoms could be an interesting study. In such a study, the symptoms after taking fructose can be compared between patients with IBS with SIBO and patients with IBS without SIBO. In addition, as bloating and flatulence are likely to be caused by increased bacterial fermentation in the bowel, it may be meaningful to explore the association between intestinal bacterial composition and symptom generation, as well as the effect of antibiotics such as rifaximin in patients with FM.

The treatments for patients with IBS are still targeted toward symptoms rather than the pathophysiology behind them. The close association between FM and IBS may suggest more specific and detailed diet plans and treatment considerations for patients with IBS. However, IBS is a disease entity that results from numerous and variable mechanisms, and many confounding factors can make the relationship between FM and IBS less clear. Thus, further welldesigned studies are needed to investigate the association between FM and IBS, the underlying mechanisms, and the effectiveness of fructose-eliminating diets.

Financial support: This work was supported by the National Research Foundation of Korea (NRF) grant funded by the Korea government (MEST) (No. 2017R1D1A1B03031924).

\section{Conflicts of interest: None}

\section{References}

1. Spiller R, Aziz Q, Creed F, et al. Guidelines on the irritable bowel syndrome: mechanisms and practical management. Gut 2007;56:17701798.

2. Mearin F, Lacy BE, Chang L, et al. Bowel disorders. Gastroenterology 2016;150:1393-1407.

3. Schumann D, Klose P, Lauche R, Dobos G, Langhorst J, Cramer H. Low fermentable, oligo-, di-, mono-saccharides and polyol diet in the treatment of irritable bowel syndrome: a systematic review and metaanalysis. Nutrition 2018;45:24-31.

4. Singh R, Salem A, Nanavati J, Mullin GE. The role of diet in the treatment of irritable bowel syndrome: a systematic review. Gastroenterol Clin North Am 2018;47:107-137.

5. Park YK, Yetley EA. Intakes and food sources of fructose in the United States. Am J Clin Nutr 1993;58:737S-747S.

6. Tappy L. Fructose-containing caloric sweeteners as a cause of obesity and metabolic disorders. J Exp Biol 2018;221:jeb 164202.

7. Buscail C, Sabate JM, Bouchoucha M, et al. Western dietary pattern is associated with irritable bowel syndrome in the French NutriNet cohort. Nutrients Published Online First: 7 Sep 2017. doi: 10.3390/nu9090986.

8. DiNicolantonio JJ, Lucan SC. Is fructose malabsorption a cause of ir- 
ritable bowel syndrome? Med Hypotheses 2015;85:295-297.

9. Goebel-Stengel M, Stengel A, Schmidtmann M, Voort I, Kobelt P, Mönnikes H. Unclear abdominal discomfort: pivotal role of carbohydrate malabsorption. J Neurogastroenterol Motil 2014;20:228-235.

10. Rao SS, Attaluri A, Anderson L, Stumbo P. Ability of the normal human small intestine to absorb fructose: evaluation by breath testing. Clin Gastroenterol Hepatol 2007;5:959-963.

11. Choi YK, Johlin FC Jr, Summers RW, Jackson M, Rao SS. Fructose intolerance: an under-recognized problem. Am J Gastroenterol 2003;98:1348-1353.

12. Melchior C, Gourcerol G, Déchelotte P, Leroi AM, Ducrotté P. Symptomatic fructose malabsorption in irritable bowel syndrome: a prospective study. United European Gastroenterol J 2014;2:131-137.

13. Goldstein R, Braverman D, Stankiewicz H. Carbohydrate malabsorption and the effect of dietary restriction on symptoms of irritable bowel syndrome and functional bowel complaints. Isr Med Assoc J 2000;2:583587.

14. Reyes-Huerta JU, de la Cruz-Patiño E, Ramírez-Gutiérrez de Velasco A, Zamudio C, Remes-Troche JM. [Fructose intolerance in patients with irritable bowel syndrome: a case-control study.] Rev Gastroenterol Mex 2010;75:405-411. [Spanish]
15. Rana SV, Malik A. Breath tests and irritable bowel syndrome. World J Gastroenterol 2014;20:7587-7601.

16. Yao CK, Tuck CJ. The clinical value of breath hydrogen testing. J Gastroenterol Hepatol 2017;32(suppl 1):20-22.

17. Ford AC, Spiegel BM, Talley NJ, Moayyedi P. Small intestinal bacterial overgrowth in irritable bowel syndrome: systematic review and metaanalysis. Clin Gastroenterol Hepatol 2009;7:1279-1286.

18. Yu D, Cheeseman F, Vanner S. Combined oro-caecal scintigraphy and lactulose hydrogen breath testing demonstrate that breath testing detects oro-caecal transit, not small intestinal bacterial overgrowth in patients with IBS. Gut 2011;60:334-340.

19. Jung KW, Seo M, Cho YH, et al. Prevalence of fructose malabsorption in patients with irritable bowel syndrome after excluding small intestinal bacterial overgrowth. J Neurogastroenterol Motil 2018;24:307-316.

20. Ghoshal UC, Kumar S, Mehrotra M, Lakshmi C, Misra A. Frequency of small intestinal bacterial overgrowth in patients with irritable bowel syndrome and chronic non-specific diarrhea. J Neurogastroenterol Motil 2010;16:40-46.

21. Shimura S, Ishimura N, Mikami H, et al. Small intestinal bacterial overgrowth in patients with refractory functional gastrointestinal disorders. J Neurogastroenterol Motil 2016;22:60-68. 